\title{
Pollux, a novel Drosophila adhesion molecule, belongs to a family of proteins expressed in plants, yeast, nematodes, and man
}

\author{
Shang-Ding Zhang, ${ }^{1}$ Judith Kassis, ${ }^{2}$ Bjorn Olde, ${ }^{3,4}$ Dervla M. Mellerick, ${ }^{1,5}$ and Ward F. Odenwald ${ }^{1,6}$ \\ ${ }^{1}$ The Neurogenetics Unit, Laboratory of Neurochemistry, National Institute of Neurological Disorders and Stroke (NINDS), \\ National Institutes of Health (NIH); ${ }^{2}$ Center for Biologics Evaluation and Research, Food and Drug Administration (FDA); \\ ${ }^{3}$ Neurogenetics Center, NINDS, NIH, Bethesda, Maryland 20892
}

\begin{abstract}
Adhesion molecules have pivotal roles in cellular processes critical to the development and maintenance of multicellular organisms. Here we describe a new member of the adhesive repertoire encoded by the Drosophila pollux $(p l x)$ gene. Marked by a novel 74 -amino-acid domain, Plx belongs to a highly conserved family with members in plants, yeast, nematodes, and man, including the human oncoprotein TRE17. Essential for viability, plx mutant analysis indicates that larval death is attributable to asphyxiation brought on by fluid-congested tracheal tubes. Ultrastructural examination of mutant tracheae reveals defects in cell-extracellular matrix contacts. During embryogenesis, Plx uniformly covers the apical surface of cellular blastoderm cells. It is later found regionally concentrated along subsets of central nervous system axon pathways and on the apical surface of the trachea's tubular epithelium. Cell attachment assays demonstrate that Plx can serve as a ligand for cell surface integrins. Plx also contains a motor neuron-selective adhesive site, multiple proteoglycan-binding motifs, and a leucine zipper: all suggest possible associations with additional components of the adhesion complex.
\end{abstract}

[Key Words: pollux; Drosophila; adhesion protein; trachea; CNS]

Received January 5, 1996; revised version accepted March 8, 1996.

Selective cell attachment to an extracellular matrix (ECM) or to adjacent cells is a fundamental part of many biological processes. Adhesive events encompass most, if not all, aspects of the development and structural maintenance of multicellular organisms (for review, see Fessler and Fessler 1989; Hynes and Lander 19921. Realized through the specific binding of surface glycoproteins, these interactions can include homo- and/or heterophilic recognitions with selective attachment of cell adhesion molecules (CAMs) most likely involving multiple combinatorial events. Many CAMs can serve as coreceptors and/or ligands for multiple specific recognition domains located on both CAMs and the ECM (for review, see Reichardt and Tomaselli 1991). In addition, certain CAMs carry out dual roles, functioning both as components of selective adhesion and as transmembrane signal transducing receptors (for review, see Hynes 19921.

Molecular analysis of genes encoding CAM and ECM

Present addresses: ${ }^{4}$ Division of Molecular Neurobiology, Wallenberg Laboratory, Lund, Sweden; ${ }^{5}$ Department of Pediatric Neurology, University of Michigan, Ann Arbor, Michigan 48109.

${ }^{6}$ Corresponding author. proteins has revealed that they belong to highly conserved families. Based on their primary structures, CAMs have been grouped into five major families: the integrins, the immunoglobulin superfamily, the cadherins, the selectins, and the leucine-rich repeat (LRR) family (for reviews or recent papers, see Hynes 1992 for integrins; Jessell 1988 and Grenningloh et al. 1990 for immunoglobulins; Takeichi 1990, 1991 and Krantz and Zipursky 1990 for cadherins; Bevilacqua et al. 1991 for selectins; Nose et al. 1992 for the LRR family). ECM families are the collagens, fibronectins, laminins, and proteoglycans (for review, see Fessler and Fessler 1989; Jolles 1994l. The modular makeup of these glycoproteins and proteoglycans is evident from the observation that many CAMs and ECMs share adhesive-structural domains that can participate in both intra- and interfamily interactions. Shared domains include the fibronectin type III repeat (Hynes 1986), the immunoglobulin repeat (Williams and Barclay 1988; for review, see Grenningloh et al. 1990), the epidermal growth factor (EGF) repeat (Hursh et al. 1987; Suyemitsu et al. 1989), lectin-binding domains (Bevilacqua et al. 1991), and leucine-rich repeats (Titani et al. 1987; Keith and Gay 1990).

In this study we provide the first molecular descrip- 
tion of the Drosophila Pollux $(\mathrm{Plx})$ protein. Our functional analysis of $\mathrm{Plx}$, coupled with its unique primary structure, reveals that it is a novel membrane adhesion molecule. Loss of Plx function results in a progressive fluid accumulation within the larva's tracheal network, culminating in congestion throughout the trachea and, ultimately, death. During larval development, Plx is deposited uniformly on the apical surface of cellular blastoderm cells and is later regionalized along subsets of central nervous system (CNS) axon pathways and on the lumen surface of large diameter tracheal tubes. Whereas cell attachment studies show that Plx can serve as a ligand for Arg-Gly-Asp (RGD)-binding integrins, it also contains additional ECM and cell-adhesion motifs plus a leucine zipper. The unique structural features of Plx exclude its placement in any of the CAM or ECM gene families described previously. However, data base searches have identified proteins in plants, yeast, nematodes, and man of similar structure whose cellular functions are currently unknown. In addition to a novel 74 amino-acid domain, these proteins also share putative ECM/cell-adhesion motifs and potential membrane-anchoring domains.

\section{Results and Discussion}

\section{Primary structure of plx and its encoded protein}

Enhancer-trap detection and cloning of $p l x$ and castor (cas), located at cytological position $83 \mathrm{C}$ on the third chromosome, has been described previously (Mellerick et al. 1992). The genomic organization and transcribed regions of these closely apposed genes are shown in Figure 1A. Deduced from DNA sequence analysis of overlapping cDNA and genomic clones, the transcribed sequence of plx consists of four exons separated by three small AT-rich introns, 58, 55, and 68 bp in length, 5' to $3^{\prime}$, respectively (Fig. 1A). No other transcription units were detected in the cloned regions flanking $p l x$ or cas (data not shown; Fig. 1A). Sequencing of genomic DNA flanking the PHlac insertion site in the H23A enhancertrap line revealed that our vector had integrated into a Doc retrotransposon (Di Nocera et al. 1983) that had inserted previously into the $3^{\prime}$ noncoding sequence of $p l x$. Despite the insertions of Doc and PHIac, the expression of plx in the H23A line was indistinguishable from those observed in Oregon-R embryos, as judged by RNA in situ hybridizations and protein immunostainings (see below). In addition, the insertions had no apparent adverse affects on the functions of either plx or cas, as the H23A line is homozygous viable. To study the phenotypic consequences of loss of either plx or cas function, we mobilized the PHlac vector in the H23A line and identified third-chromosome recessive lethal mutants that were generated by the vector's imperfect excisions (Fig. 1A; Mellerick et al. 1992). In our previous report, which focused on cas, analysis of these mutants (complementation tests, Southern analysis, and expression studies) identified two separate allelic groups corresponding to mutations in plx or cas.
The plx mRNA contains a single long open reading frame (ORF) that encodes a 732-amino-acid protein (Fig. 1B). Inspection of the protein's predicted primary structure reveals that it contains multiple CAM and ECM adhesion motifs. Plx has an RGD integrin recognition/ attachment site (Pierchbacher and Ruoslahti 1984), a Leu-Arg-Glu (LRE) motor neuron-selective attachment motif (Hunter et al. 1989), multiple proteoglycan adhesion sites (Cardin and Weintraub 1989), and potential disulfide-bridging residues. Plx also contains a proteinprotein dimerization domain: the $\alpha$-helical leucine zipper (Landschulz et al. 1988).

A hydropathicity plot (Kyte and Doolittle 1982), employed to predict hydrophilic and membrane-associated hydrophobic domains, indicates that a centrally located stretch of 44 predominantly nonpolar amino acids (residues 262-306; Fig. 1B,D) has a sufficient number of hydrophobic residues to span a lipid bilayer twice. The hydropathicity plot also reveals that Plx lacks an obvious amino-terminal transmembrane insertion signal peptide. The absence of an amino-terminal signal sequence in transmembrane or secreted proteins is not unprecedented. The transmembrane proteins p33, band 3, and the influenza neuraminidase all lack amino-terminal signal sequences (discussed in Strubin et al. 1984). Although the membrane polarity of Plx is currently unknown, its central hydrophobic domain may serve a dual function as both a transmembrane insertion signal and a membrane anchor. Plx contains both $\mathrm{N}$-linked (NXS/T) and O-linked (SG) oligosaccharide-attachment sites (Fig. $1 \mathrm{~B}, \mathrm{Cl}$. One of the three potential O-linked sites, residue 586 (Fig. IB), is flanked by the consensus glycosaminoglycan-linkage sequence for the Xyloside substitution of serine residues in proteoglycans (Bourdon et al. 1987).

Plx is related to proteins expressed in plants, yeast, nematodes, and man

With the exception of the above-mentioned adhesion motifs, data base homology comparisons failed to place plx in any of the CAM and ECM gene families described previously. However, 20 structurally related proteins of unknown cellular function, expressed in phylogenetically distant organisms, were identified. The most striking feature shared among these proteins is a similarly positioned novel 74-amino-acid domain (Fig. 1B,E), which we have named PTM after the first three proteins discovered to contain it: the Drosophila Plx, the human oncoprotein TRE17 (oncoTRE17, Nakamüra et al. 1988), and a human Myeloid cell line-expressed protein (GenBank accession no. D13644). Subsequent searches have identified other PTM family members: In Arabidopsis thaliana, three partial cDNA expressed sequence tags (ESTs); an EST from the shoots of oryza sativa (rice); three genomic ORFs in Saccharomyces cerevisae; two genomic ORFs and two ESTs in Caenorhabditis elegans; and in man, an additional seven ESTs. Optimal alignment of 10 representative PTMs (Fig. 1E) demonstrates an identity of $\geqslant 50 \%$ in $83 \%$ of the domains' residues. Furthermore, $35 \%$ of the positions have $\geqslant 90 \%$ identity 
or similarity. Secondary structure analysis of the PTMs predict a domain with a globular/folded tertiary conformation, comprised of multiple short $\alpha$-helixes and $\beta$-sheets interrupted by $\beta$ turns or structure-breaking residues (Chou and Fasman 1978; Garnier et al. 1978).

One of the conserved blocks of homology within the domain, the pentapeptide Gly-Tyr-Cys-Gln-Gly (GYCQG; Fig. 1E, positions 51-55|, is found in 16 of 20 identified PTM domains, and all 20 contain the invariant tripeptide GYC. This identical pentapeptide has been reported in the extracellular domain of the integrin $\alpha$-subunit of the human fibronectin receptor (GYCQG, residues 161-165; Argraves et al. 1987). A related peptide is also found in the integrin $\alpha$-subunit extracellular domains of the human vitronectin receptor (GFCQG, residues 152-156; Suzuki et al. 1986). Disulfide linkage studies on the human fibronectin receptor have shown that the peptide's central cystine residue can participate in disulfide links (Calvete et al. 1991), suggesting that the PTM domain may accommodate a looped disulfide- linked structure with another region of the protein or serve as a disulfide bridge between other proteins. Alternatively, the peptide may have an additional or unique function shared by PTM proteins and integrin $\alpha$-subunits.

Comparisons among PTM proteins whose complete ORFs have been determined (Plx, 732 amino acids; the human oncTRE17, 786 amino acids; and the human myeloid cell line protein, 842 amino acids), reveal that their PTM domains occupy nearly identical positions relative to their predicted amino termini: starting at residues 141, 138, and 139 for Plx, oncTRE17, and the myeloid protein, respectively. Hydropathicity plot alignments show that Plx and oncTRE17 both have potential membrane-spanning hydrophobic regions residing at identical positions relative to their amino termini (Fig. ID). Similar to Plx, both the predicted oncTRE17 and myeloid proteins lack an amino terminus transmembrane signal peptide sequence. All three have multiple proteoglycanbinding motifs, glycosylation sites, and potential disul-
Figure 1. Plx shares a novel 74-aminoaacid domain with proteins expressed in plants, yeast, nematodes, and man. $(A)$ The. genomic organization of $p l x$ and cas showing the Doc retrotransposon and the PHlac enhancer-trap vector integration sites. A restriction map indicating the positions of BamHI (B), EcoRI (E), and Xbal (X) sites is aligned with the plX and cas transcription units, which are transcribed from opposite DNA strands. Hatched areas represent the longest ORFs in the transcripts; introns are indicated by angle bars. The broken lines indicate the genomic regions of $p l x$ and cas that suffered deletions during imperfect excisions of PHlac. (B) The 732 amino acids encoded by the plx transcript's longest ORF are shown. Analysis of the protein's primary structure revealed various structural features that include potential proteoglycan/ heparin-binding sites /residues 2-10, 49-52, $83-87,470-474,503-507$, and 691-694; underscored), LRE motor neuron and RGD integrin adhesion sites/residues 15-17 and 102-104, respectfully; boxed with broken lines), possible $\mathrm{N}$-linked glycosylation sites at positions 76,551 , and 600 ), a consensus O-linked glycosylation site (position 586), the PTM domain (residues 141-214; boxed), a putative transmembrane hydrophobic region (residues 262-306; underscore), and a leucine zipper motif (residues 411-439; underscored with the residues conforming to the zipper's 3-4 rule double underscored). (C) A linear representation of the Plx protein showing relative positions of the putative heparin binding motifs $|O|$; the LRE and RGD adhesion sites; potential Nand O-linked glycosylation sites $\mid \nabla$ and $\boldsymbol{\Lambda}$, respectively); the PTM domain; a potential membrane spanning hydrophobic region;

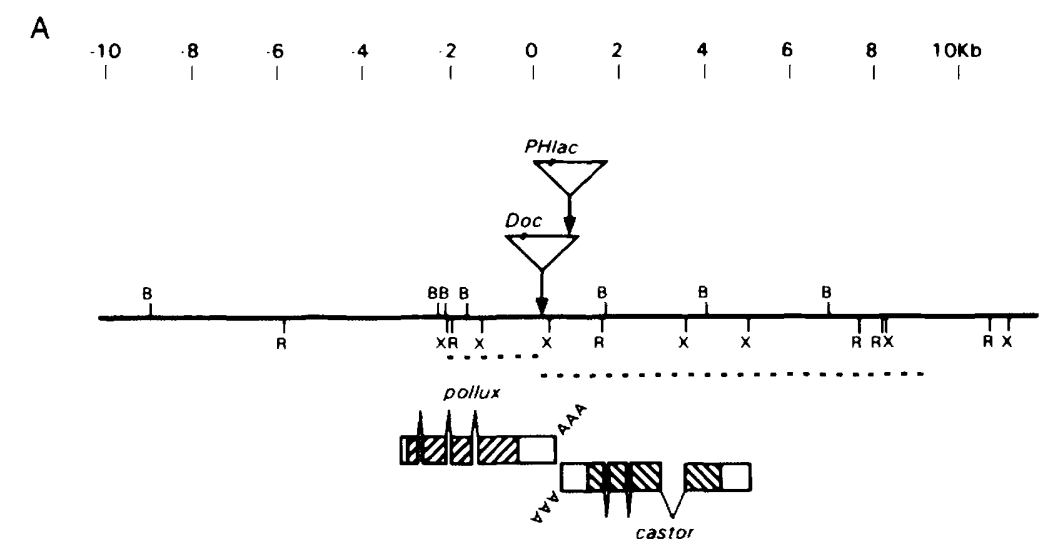

B

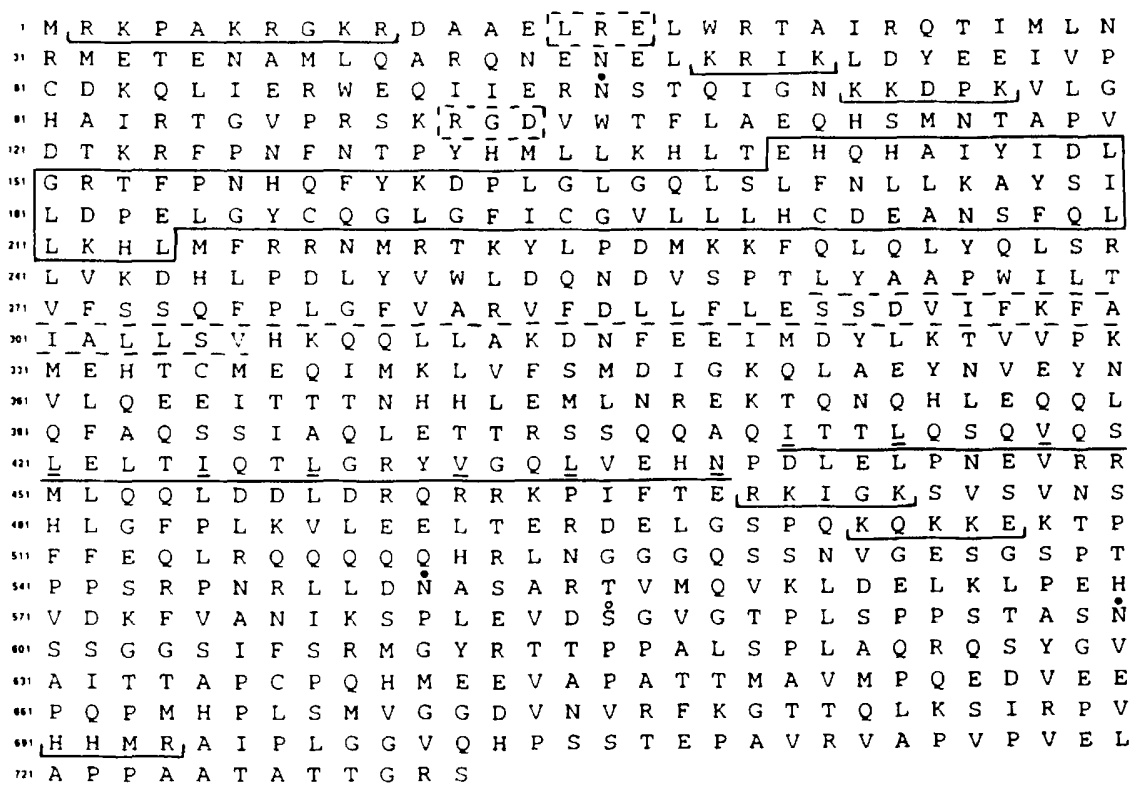

(Figure 1. See facing page for $\mathrm{C}-\mathrm{E}$ and legend.) 
fide linkage sites, and the myeloid protein contains the $\alpha_{2} \beta_{1}$ integrin-binding site Asp-Gly-Glu-Ala (Staatz et al. 1991$)$.

In man, different PTM-encoding transcripts have been found in placenta, infant brain, adult retina, adult heart, and in cell lines derived from immature myeloid and T-lymphoblastic leukemia cells. oncTRE17 transcripts, initially isolated from Ewing's sarcoma cells (Nakamura et al. 1988), have now been detected in a wide variety of human cancer cells (Nakamura et al. 1992). Although the cellular distribution of the oncTRE17 protein is currently unknown, its structural homology to Plx suggests that its transforming capacity may be linked to a cellsurface signal transduction role. The expression of PTM proteins in organisms as taxonomically dissimilar as plants and man, and in so many different tissues undergoing development further suggests that these proteins carry out adhesive roles in all multicellular organisms.

\section{Regionalized expression of Plx during larval development}

During oocyte development, plx mRNA is maternally expressed in the egg chamber's nurse cells (Fig. 2A). plx expression is first detected in the oocyte support cells shortly after they are formed, and as development progresses the $p l x$ in situ signal intensifies suggesting a cumulative increase in steady-state mRNA levels. Starting at oocyte stage 10, when the cytoplasmic contents of the nurse cells are transported into the oocyte [oogenesis stages according to King (1970)], plx transcripts appear distributed evenly throughout the oocyte. In situ hybridizations carried out on embryos undergoing cellularization indicate that plx mRNA is taken up into the newly formed blastoderm cells (Fig. 2B). Shortly thereafter, Plx protein is detected in the embryo. Serial sections through immunostained cellular blastoderm embryos revealed that Plx is distributed uniformly on the apical surface of the blastoderm cells (Fig. 2C). No plx message or protein was observed in the embryo's pole cells. During gastrulation, levels of the evenly distributed mRNA and protein diminished such that by stage 9 little or no staining was observed [embryo stages according to Campos-Ortega and Hartenstein (1985)]. plx transcription is next detected in the CNS of late stage 11 embryos. Identified by their position within the developing ganglia, as
C
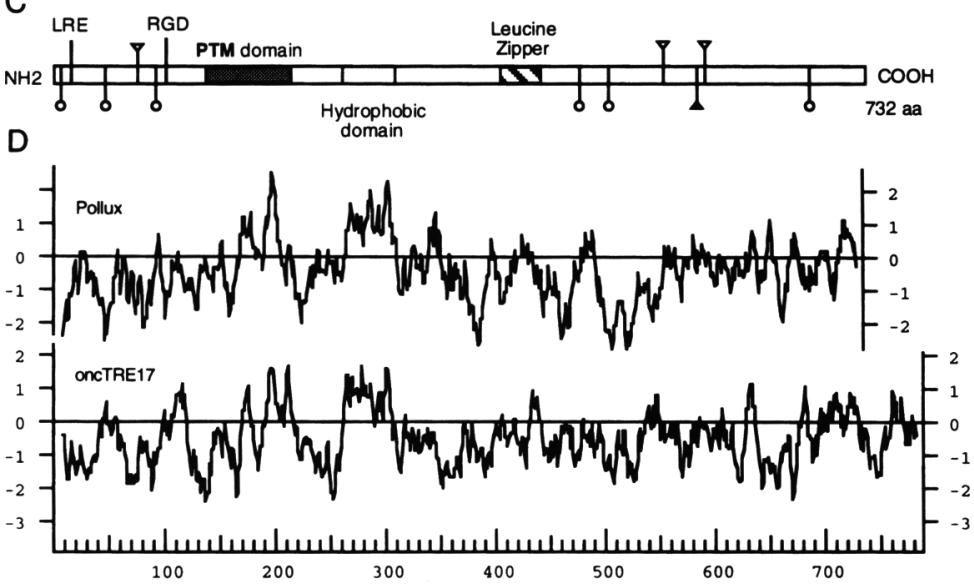

E

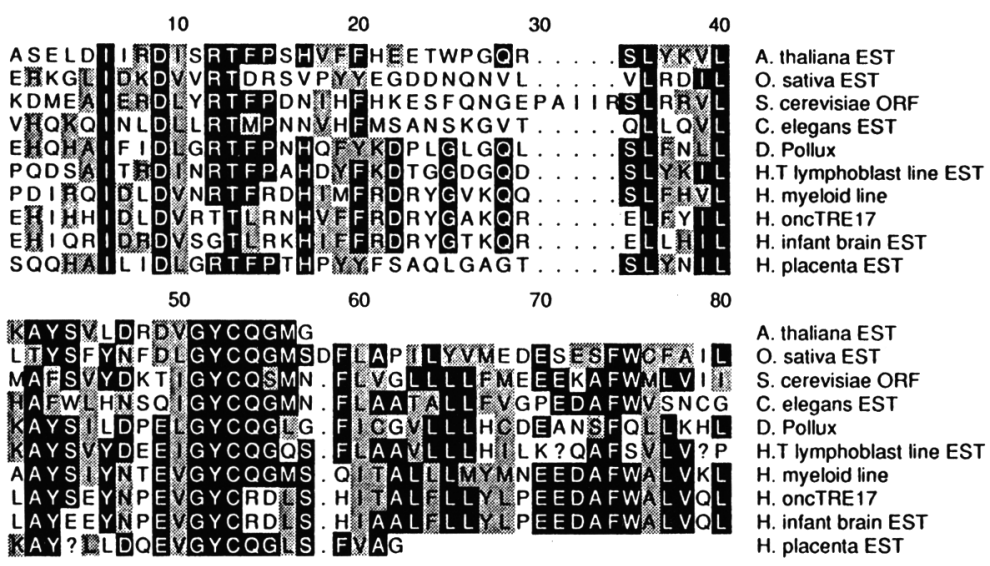

and its leucine zipper. $(D)$ Hydropathicity plot alignments of the 732-amino-acid Plx and the 786-amino-acid oncTRE 17 reveal similiarly positioned hydrophobic and hydrophilic domains. Both have centrally located potential transmembrane spanning hydrophobic residues equal distance from their respective amino termini (positive ordinate values indicate hydrophobic residues). (E) The PTM domain is highly conserved. Optimal alignments of PTM domains from an A. thaliana EST /Genbank accession no. T12947); an oryza sativa (rice) shoot EST (D41451); a $S$. cerevisae genomic ORF (Z48149); a C. elegans EST (D27845); the Drosophila Plx protein (residues 141-214); a human lymphoblast cell-line EST (Z16174); a predicted 842 -amino-acid human protein expressed in a myeloid cell line (residues 139-212) (D13644); the predicted 782-amnio-acid human oncoTRE17 protein (residues 138-211) (X63546); an EST from a human infant brain library (F08442); and partial sequence from a human placental EST (R24919). The particle Arabidopsis and human infant brain PTM domains were deduced from ESTs containing only two-thirds of their respective PTM encoding sequence. Question marks (?) in the placenta and lymphoblast sequences represent EST sequence uncertainties. Gaps in the amino acid residues, indicated by dots, were introduced for optimal alignment. Identical amino acids that occupy $\geqslant 50 \%$ of the positions in a column are shown with white letters and black backgrounds with similar residues highlighted by shading [similarity criteria according to Lipman and Pearson (1985)]. 
Figure 2. Developmental expression of $p l x$ mRNA and its encoded protein. The distribution of $p l x$ message $(A, B, D, G)$ or its encoded protein $(C, E, F, H, I)$ is shown by RNA in situ hybridization with digoxigenin-labeled riboprobes (blue) or protein immunostaining (brown) with anti-Plx mouse antibodies. $\{C, F, G, I\}$ Ten-micronthick transverse sections of embryos that were embedded in plastic after wholemount staining. $(A)$ Developing egg chamber; plx message is detected in all nurse cells /oogenic stage 10B; inset, stage 9|. During stage 11 , plx transcripts become evenly distributed throughout the oocyte (not shown). $(B, C)$ Cellular blastoderm; at cellularization, plx transcripts $(B)$ are concentrated at sites of cell formation in the periphery, whereas its encoded protein $(C)$ is detected on the apical surface of the newly formed blastoderm cells. $(D-G)$ CNS expression; $(D, G)$ By embryonic stage 14 , plx mRNA is detected in most (but not all) neuron cell bodies throughout the CNS. No expression was observed in neuroblasts. $\langle E, F\rangle$ Immunostaining reveals that Plx protein is selectively concentrated in axon fascicles that make up the ventral cord's longitudinal connectives ( $E$ is a dorsal view of a stage 14 dissected ventral cord) and the supraoesphageal commissure (arrowhead in $F$ ). The arrow in $F$ marks the surface of an immunostained ventral cord cell body. Note that within
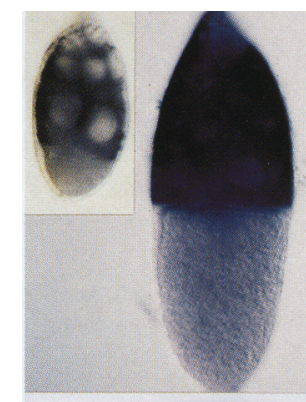

A

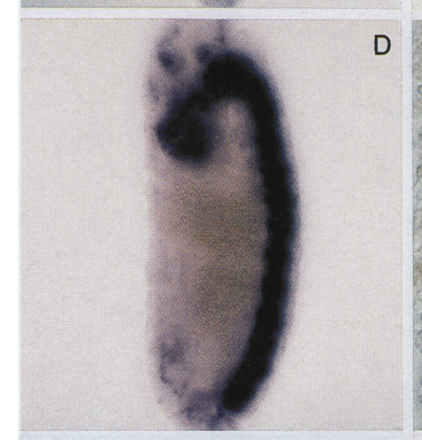

D
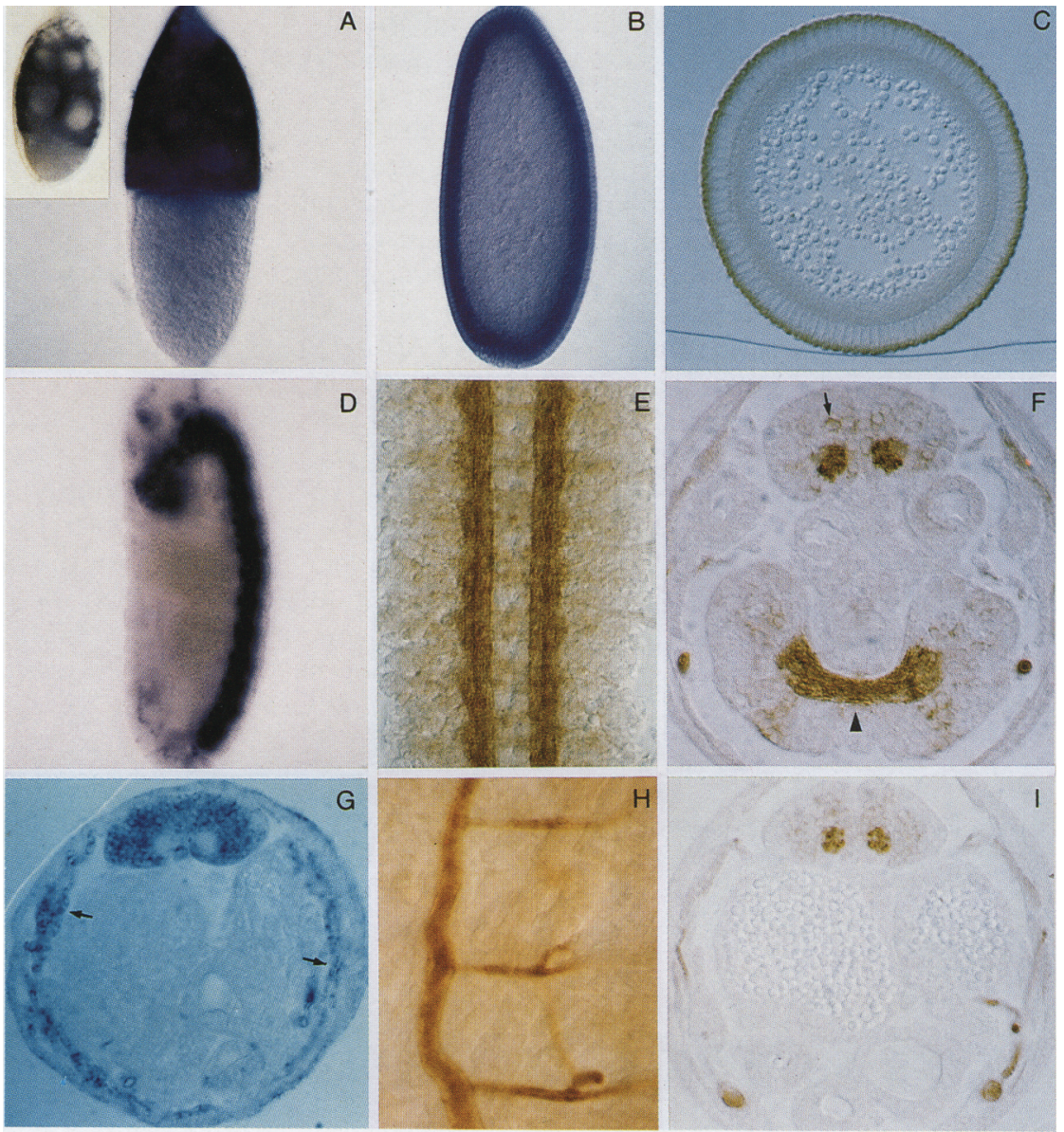
the brain hemispheres $(F)$, cell body immunostaining is restricted to subsets of bilaterally symmetrical cells. $(G-I)$ Tracheal expression; starting at stage 14 , plx message $|G|$ is detected in the epithelium lining the tracheal tubes of the dorsal and lateral trunks (see arrows). By late stage 15, Plx protein is detected both in the lumen of the large diameter, major tracheal branches and lining the surface of its epithelium $(H, I)$.

observed in serial transverse sections, newly formed neurons throughout the CNS express plx message (data not shown). plx transcripts were not detected in neuroblasts or ganglion mother cells at any stage of CNS development. In addition, no message or protein was observed in the peripheral nervous system. As the number of postmitotic cells increase during CNS development, so does the number of $p l x$-expressing cells such that by stage 14 , most if not all neurons contain plx transcripts (Fig. 2, D and G). Plx protein is first detected in the CNS on the surface of neuronal cell bodies, during late stage 12 . Starting at stage 13, Plx begins to accumulate uniformly along axon tracts that extend the entire length of the ventral cord's longitudinal connectives (Fig. 2E,F,I). As ventral cord contraction continues, serial sections through whole-mount immunostained stage 14 or older embryos, reveal immunostaining on cell surfaces outlining subsets of cell bodies and show that most axon fascicles (although not all) traversing the longitudinal connectives accumulate Plx (see Fig. 2F,I). At the light-microscopic level of resolution, Plx immunostaining within the fascicles appears to be associated with axonal plasma membranes and the periaxonal space between the bundled axons. However, ultrastructural localization will be required to identify its exact position within fascicles.

No appreciable Plx immunostaining was observed in the ventral cord's commissures or in the lateral projecting axon tracts (Fig. 2E,F,I). The restricted or regional deposition of Plx within subsets of axon pathways that traverse both commissures and connectives is a characteristic shared by many axonal CAMs and ECM glycoproteins in both vertebrates and invertebrates (for review, see Goodman and Doe 1993). The regionalization of Plx may be attributable to directed deposition through a specific transport/translocation mechanism and/or its target receptor molecule is regionalized within axon fascicles. In contrast to the axon fascicles residing in the ventral cord commissures, fascicles within the brain's supraoesphageal commissure, which interconnect the cephalic lobes, accumulate high levels of Plx (Fig. 2F). Serial transverse sections show that Plx is again regionally distributed within the fascicles. Within the developing brain's supraoesphageal ganglion, little or no $\mathrm{Plx}$ was found on axon surfaces before they enter or after they exit this commissure. In addition to the heavy la- 
beling on the supraoesophageal commissure, subsets of symmetrically positioned cell bodies, presumably neurons, within the cephalic lobes also have detectable levels of Plx on their surfaces (Fig. 2F).

During the initial phase of axonogenesis, when the first longitudinal and commissural pathways are established, Plx protein was not found on the pioneering axons or associated with newly formed axon fascicles. The late appearance of Plx within the developing CNS, relative to membrane proteins involved in axonogenesis, suggests that its role in the CNS is one of maintenance of function rather than of establishing its structure. Plx's motor neuron-selective adhesive site (LRE; Fig. 1) may function to maintain proper motor neuron axonal-ECM contact within these fascicles.

Like other Drosophila axonal adhesion glycoproteins such as Neuroglian (Elkins et al. 1990), Plx is also expressed in the tubular tracheal epithelium (Fig. 2G). Similar to $p l x$ 's late activation during CNS development, $p l x$ message is first detected in cells lining the major, large diameter tracheal tubes shortly after fusion of the dorsal trunk metamers. No expression was detected during the primary phase of tracheal development particularly in the tracheal pits or during initial branch formation and early outgrowth of the dorsal and lateral tubes (for review of tracheal development, see Manning and Krasnow 1993). In addition to the dorsal and lateral trunks, plx message was detected in other major branches. However, expression was not detected throughout the tracheal tree. Little or no plx message was found in cells making up the smaller tubes nor was it detected in the smallest branches of the trachea, the tracheole.

Plx protein is first observed in the trachea shortly after its message is detected. Examination of stage $15 \mathrm{em}$ bryos, in whole-mount and in serial transverse sections, revealed that Plx localized to the apical surface of the epithelium (Fig. 2H,Il). The level of Plx immunostaining corresponds with tracheal tube diameters. Whereas the dorsal and lateral trunks and their immediate branches had consistently high levels of Plx immunostaining, little or no staining was observed on or in the smaller branches or associated with tracheoles. At embryonic stage 15, when the tracheal tubes are filled with fluid, $\mathrm{Plx}$ is also detected in the lumen of the dorsal and lateral trunks (Fig. $2 \mathrm{H}, \mathrm{I}$ ), suggesting that all or a cleaved portion of Plx may dissociate from the epithelial cell's plasma membrane.

The late appearance of Plx in the trachea and its presence in the lumen is consistent with it being part of, or associated with, the trachea's cuticular ECM, which is formed during stages 15 and 16 of development. The regionalized distribution, confined to predominantly the major, larger diameter tubes, further suggests that Plx may associate with or make up a particular part of the cuticular ECM substructure known as the endocuticle (or procuticle). The cuticular ECM intima of large diameter tubes is comprised of an outer (luminal) epicuticle and an inner procuticle layer. The procuticle consists of a filamentous matrix that fills the taenidial folds between the epicuticle and the epithelium /see below; for reviews, see Noirot and Noirot-Timothee 1982; Manning and Krasnow 1993). The procuticle is not part of the cuticular intima of smaller diameter tubes or in tracheoles.

\section{$\mathrm{Plx}$ is a ligand for cell-surface integrin receptors}

Based on the expression of Plx on cell surfaces and the presence of putative CAM and ECM adhesion sites within its primary structure, we next carried out a series of experiments to determine whether Plx could promote cell adhesion. To determine whether the integrin recognition motif of Plx was functionally active and could initiate cell attachment, we assayed the ability of cultured human MG63 cells (Ruoslahi et al. 1982) to adhere to microtiter wells coated with affinity-purified, fulllength recombinant $\mathrm{Plx}$ (Fig. 3A-D). Under standard cell attachment assay conditions, MG63 cells, which express the $\alpha_{5}$ and $\beta_{3}$ integrin subunits (Adams and Lawler 1993|, require a substratum containing functionally active RGD recognition sites for attachment. Like the positive control (fibronectin-coated wells; data not shown),

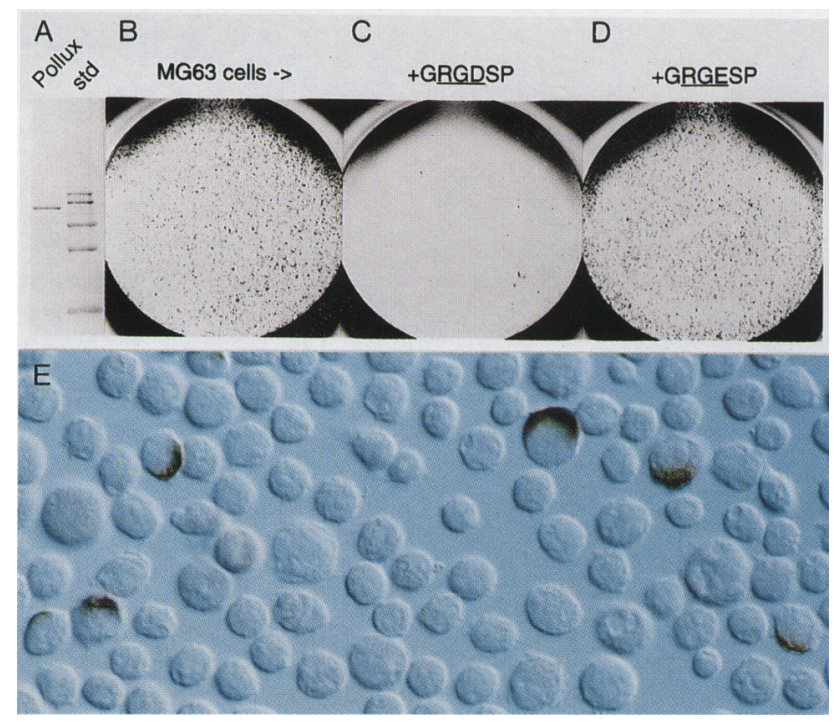

Figure 3. Plx is a ligand for RGD-binding integrins and assumes an asymmetrical distribution on cell surfaces. $(A-D)$ Cell attachment assays demonstrate that Plx's integrin attachment RGD site is functional. Affinity-purified recombinant Plx $|A|$ can serve as a substrate for MG63 cell attachment to the surface of microtiter wells coated with Plx $|B|$ /see Materials and methods). This attachment can be specifically blocked by preincubating the cells with a peptide containing the RGD motif $(C)$ but not with a similar peptide that lacks the integrin RGD-binding site $|D|$. Note the protein standards in $A$ are $\beta$-galactosidase (116.3 kD), phosphorylase b $(97.4 \mathrm{kD})$, BSA $(66.3 \mathrm{kD})$, glutamic dehydrogenase $(55.4 \mathrm{kD})$, and lactate dehydrogenase $(36.5 \mathrm{kD})$. (E) Plx displays extracellular epitopes on the surface of transfected Drosophila Schneider S2 cells. Plx immunostaining was carried out in the absence of membrane-permeablizing agents. Note that Plx accumulates on the cell surfaces in a polarized manner. 
the MG63 cells attached to Plx-coated wells (Fig. 3B). Little or no attachment was observed in uncoated wells or in wells coated with bovine serum albumin (BSA) (data not shown). When MG63 cells were pretreated with the hexapeptide Gly-Agr-Gly-Asp-Pro-Ser $>95 \%$ of the attachment was blocked compared with nontreated cells (Fig. 3C). However, pretreatment with a similar peptide (Gly-Agr-Gly-Glu-Pro-Ser) that lacks an RGD recognition motif failed to significantly block cell attachment to the Plx substratum (Fig. 3D), demonstrating that Plx can function as an integrin ligand through its RGD motif.

Previous studies have shown that four of the Drosophila axonal glycoproteins involved in CNS axon fasciculation can mediate homophilic cell adhesion when expressed in cultured Drosophila Schnieder S2 cells (for review, see Goodman and Doe 1993|. Although Plx appears late in CNS development, indicating that it may not have an active role in fasciculation, its restricted expression in subsets of axon fascicles suggests that it may function to maintain fascicle structure through homophilic interactions. To determine whether Plx can promote cell aggregation through homophilic interactions, we performed cell aggregation experiments with transformed S2 cells (Snow et al. 1989; Elkins et al. 1990; Nose et al. 19921. Our cell lines that expressed a fulllength $\mathrm{Plx}$, under the control of the metallothionein promoter (Bunch et al. 1988) or in transiently transfected S2 cells using the same copper-activated plx transgene, failed to produce significant cell aggregation /data not shown|. Although no homophilic interactions were detected, Plx may require additional cofactors or modifications to promote cell adhesion, conditions not provided by the S2 cells. Immunolocalization of Plx on the surface of the transformed $\mathrm{S} 2$ cells, in the absence of membranepermeablizing detergents, demonstrated that $\mathrm{Plx}$ accumulates asymmetrically on plasma membranes and displays extracellular domains (Fig. 3E). The membrane capping of Plx was not caused by antibody cross-linking as the cells were fixed before immunostaining. The asymmetry of Plx expression on the surface of the S2 cells is consistent with its in vivo regionalization and may indicate a selective interaction with other membrane proteins and/or with cytoskeletal components.

\section{Loss of plx triggers excessive fluid accumulation} in the larval trachea

Plx immunostaining, performed on embryos from our mutant alleles identified the maternal Plx contribution on the surface of homozygous $\mathrm{plx}^{-}$cellular blastoderm embryos but failed to detect any zygotically expressed Plx (data not shown), indicating that the deletions generated by the pHlac's imperfect excisions (Fig. 1A) created protein-null mutations. Complementation tests between the $\mathrm{plx}^{-}$and cas ${ }^{-}$alleles demonstrated that the loss of one of these genes did not adversely affect its close neighbor (Mellerick et al. 1992). Immunostaining with antibodies that recognize the surface of all CNS axons and/or neuronal cell bodies (mAb BPl02, mAb
BP104, or anti-HRP polyclonal antibody) did not reveal any observable differences between $p l x$ mutants and the wild-type CNS. No gross differences among axon densities, cell body numbers, or volume of the brain or ventral cord ganglia at any stage of embryonic development were observed. Likewise, immunostainings with antibodies that decorate subsets of axons traversing ventral cord longitudinal connectives and/or commissures (mAb 22C10, Zipursky et al. 1984; Fasciclin II mAb, Van Vactor et al. 1993) failed to identify any defects in axonogenesis or structural abnormalities in fascicles that make up these axon tracks. In addition, no gross structural defects in the trachea's tubular network were observed in $p l x^{-}$embryos, as judged by immunostaining with the 2A12 antibody (Patel 1994) that binds uniformly to the surface of the tracheal epithelium. The lack of observable structural abnormalities in the developing embryo suggests that functionally redundant proteins may exist. Interestingly, loss-of-function mutations in other Drosophila axonal adhesion glycoproteins such as Neuroglian and the Fasciclins I and III also fail to produce structural abnormalities (Elkins et al. 1990; for review, see Grenningloh et al. 1990). Alternatively, the maternal contribution of $p l x$ may be sufficient to allow for normal development to proceed in the $p l x^{-}$embryo.

Consistent with the absence of any gross phenotypic differences between our mutant $p l x$ alleles and wild-type embryos, $p l x^{-}$larvae exit their egg chambers and show no physical or behavioral abnormalities associated with locomotion, feeding, or avoidance responses to touch and bright light. Like their wild-type siblings, newly hatched $p l x^{-}$larvae have gas-filled trachea. However, starting $\sim 12 \mathrm{hr}$ after hatching, the plx ${ }^{-}$larva start to accumulate excessive fluid in their tracheae. First detected in their dorsal trunks, the fluid pockets appear in multiple, randomly positioned locations along the dorsal tubes, separating/sealing off adiacent gas-filled regions of the lumen (Fig. 4B,C). Direct observation of larval feeding and migration on the surface of yeasted grape agar plates revealed that the fluid was not cleared from the tubes, and its volume, as judged by the size and number of fluid filled areas, increased with time. The dynamics of the fluid accumulation was essentially the same if the $p l x^{-}$larva were cultured on hardened grape agar plates without yeast or excessive moisture, indicating that the fluid buildup was not caused by fluid inhalation but rather caused by the tracheal epithelium's inability to either block entry of body fluids and/or transport body fluids out of the lumen. Alternatively, the excessive fluid could be triggered by defects in cuticle molting, such as excessive release of fluids by the epithelial cells during premature cuticle apolysis. $p l x^{-}$larva start to die between 18 and $24 \mathrm{hr}$ after hatching with $100 \%$ mortality at or just before the second-instar molt. Coincident with the excessive fluid congestion was the onset of slower locomotion and delayed or sluggish response to both touch and light stimuli. No breaks in the tracheal tubes or any other gross structural defects were observed in these mutant larvae. Just before death, at a time when all observed mutants had most of their tracheal tubes 


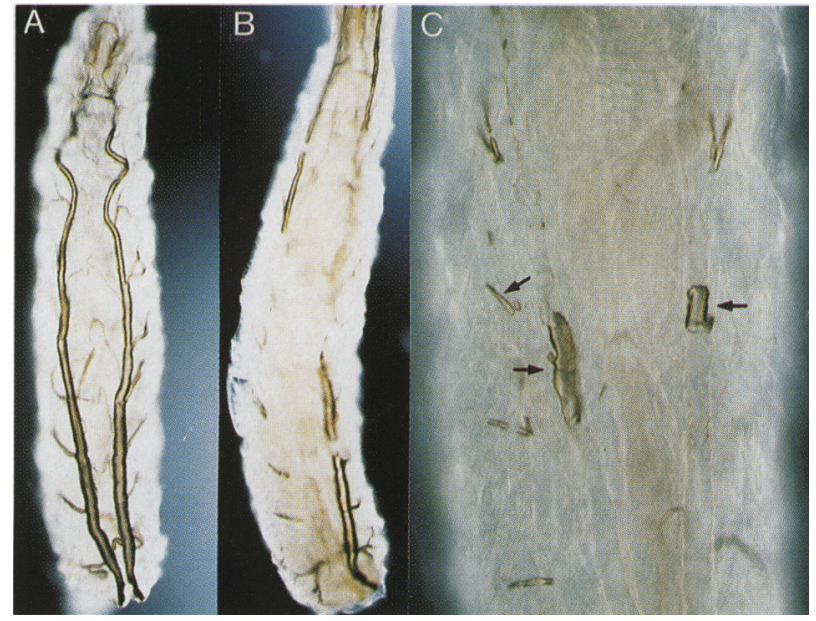

Figure 4. Loss of $p l x$ function results in a progressive accumulation of fluid within tracheal tubes and, ultimately, larval death. $\{A, B \mid$ Phase-contrast dorsal views of living second instar larva $\{A$, wild type; $B, p l x)$. Starting $\sim 12$ hr post-hatching, plx larvae begin to show signs of excessive congestion in the large dorsal trunks of their tracheal tree. Note, fluid-filled sections of the dorsal and lateral tracheal tubes are optically transparent. (C) The fluid continues to accumulate filling most of the major branches and just before death, only small pockets of gas (arrows) remain in the $p l x^{-}$tracheae.

filled with fluid (Fig. 4C), they slowed or ceased crawling and repeatedly raised their posterior spiracles upward. Death followed shortly after this "gasping for air" behavior.

\section{$\mathrm{Plx}$ is required to maintain proper tracheal}

\section{ECM structure}

To determine whether structural defects existed in trachea of $p l x^{-}$larva, unresolvable by light microscopy, we next examined their ultrastructure. Electron microscopic views of serial transverse sections, collected from the seventh and eighth abdominal segments of 6- to 10 hr-old and older larva, failed to identify structural defects within the trachea's epithelial cells or in their contacts with other epithelial cells. No breaks between cells were observed and their interlocking tight junctions appeared normal. In addition, the outer basement lamina of $p l x$ trachea, surrounding the tracheal epithelium's outer surface, also appeared normal.

However, structural differences between wild-type and $p l x^{-}$trachea were observed in the epithelial cell's cuticular ECM (Fig. 5A,B). In wild-type trachea, the premolt cuticle consists of a regularly folded (electrondense) epicuticle that protrudes into and lines the lumen cavity (Fig. 5A). Underlining the epicuticle is an inner, more electron-lucent, endo- or procuticle (for review, see Noirot and Noirot-Timothee 1982; Manning and Krasnow 1993). The procuticle, found in larger diameter tubes, consists of a fibrillar matrix that fills the intrataenidial area between the epicuticle and surface of the epithelial cells (Fig. 5A). In smaller branches of the trachea, the procuticle becomes thinner and is absent from the tracheoles (Noirot and Noirot-Timothee 1982). Although the apical surface of the cuticle appeared normal and no structural breaks were detected, the epicuticle of the $p l x^{-}$trachea was separated from the underlining epithelium (Fig. 5B). In addition, the procuticle's fibrous matrix was also reduced or missing in the taenidial folds (Fig. 5B). The loss of epicuticle contact with the epithelium and the reduced/disorganized filamentous network within the procuticle was particularly evident in the maior, large, and intermediate tracheae. Conversely, no significant differences between wild type and $p \mathrm{l}^{-}$were observed in the small diameter tubes. The loss of the fibrillar matrix within the procuticle appeared greatest in the taenidial folds where clearings devoid of fibrous material were frequently observed (Fig. 5B). The cuticular ECM defects were observed in $p l x^{-}$tracheae with and without detectable levels of excessive fluid accumulation.

The tracheal epithelium's reduced contact with its epicuticle and the observed disorganization in the procuticle's fibrous matrix of $p l x^{-}$trachea suggest that Plx may function to ensure proper epithelium-epicuticle contact

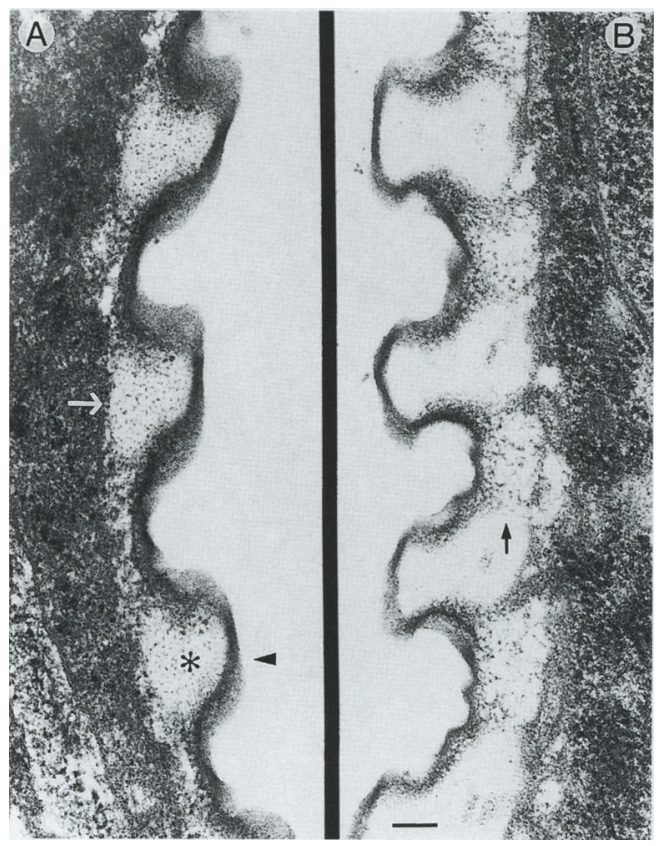

Figure 5. $\mathrm{Plx}$ is required for proper contact between the tracheal epithelium and its cuticular ECM. Ultrastructural views are shown of longitudinal tracheal sections from the lateral branches of wild-type $(A)$ and $p l x^{-}(B)$ first-instar larva. In wildtype tracheae, the cuticular ECM intima is comprised of an outer (luminal) electron-dense epicuticle that protrudes into the lumen demarcating the taenidial folds (arrowhead in $A$ ) and an inner, more electron-lucent, filamentous-network called the procuticle or endocuticle that fills the the taenidial folds $\left({ }^{*}\right)$ between the taenidum and the epithelial cell surface (arrow). (B) In plx tracheae, the procuticle's fibrous matrix is reduced/ disorganized and, in the taenidial folds, the epicuticle has separated from the epithelium (arrow). Bar in $A$ and $B, 0.3 \mu \mathrm{m}$. 
through adhesive links with the ECM. When released from the epithelial surface, Plx may also provide an organizational role in the procuticle's filamentous matrix by cross-linking components of the procuticle's ECM. During apolysis, a process whereby the tracheal epithelium sheds its cuticle, ECM degrading enzymes are released by the epithelium triggering the epicuticle's separation from the epithelium. Premature apolysis could be induced by a number of factors including loss of ECM contact and/or a premature exogenous signal to initiate apolysis. We cannot currently distinguish between these two possibilities. However, in the absence of any observable breaks in the plx ${ }^{-}$epicuticle, an event associated with apolysis, our findings suggest that the epithelialECM separation is attributable to loss of adhesive contacts and/or defects in the procuticle's organization. The reduced contact most likely compromises the trachea's structural integrity, interfering with its ability to insulate/seal off its lumen from body fluids.

\section{Concluding remarks}

In this study we report on the molecular and functional analysis of plx, a Drosophila gene that is essential for larval viability. Localization of its message and encoded protein during embryonic development has revealed three temporal phases of expression, a maternal and two zygotic phases, that ultimately result in the deposition of its encoded protein on restricted cell surfaces and its release from the tracheal epithelium. Our in vitro analysis of its encoded protein shows that Plx can serve as a substrate for cell attachment, an adhesion event mediated through its integrin recognition site. The presence of multiple CAM and ECM glycoprotein-binding sites in Plx further suggests that it may interact with additional elements of the adhesion complex. Primary structure comparisons with other adhesion molecules reveal that $p l x$ does not belong to any of the gene families coding for CAM or ECM glycoproteins described previously. Thus, its unique identity leads us to propose that Plx represents a novel adhesion protein that may serve a dual role as both a CAM and, when released from cell surfaces, a component of the ECM. The observation that plx shares considerable sequence similarity with proteins expressed in plants, yeast, nematodes, and man indicates that this gene belongs to a highly conserved family that is likely to be part of the adhesive repertoire of many if not all multicellular organisms. As judged by the pleiotropic expression of $p l x$ and the identification of multiple human PTM ESTs isolated from different tissues and different developmental stages, it is easy to speculate that PTM proteins may carry out membrane-associated roles in a wide variety of cellular events.

\section{Materials and methods}

Drosophila stocks

Standard Drosophila husbandry procedures were employed. Phenotypic analysis of $p l x$ mutants was performed on the $J F$,
$\$ 180$, and $\$ 416$ lines that were generated by imperfect excisions of the PHlacZ vector in the H23A line (Mellerick et al. 1992). For identification of homozygous $p l x$ embryos, lines were balanced with TM3 P[ftz lacZ) (Hiromi et al. 1985; Nambu et al. 19901. For identification of mutant larva, lines were balanced with TM6B containing the dominant Tubby phenotypic marker (Lindsley and Zimm 1987).

Molecular biology

DNA cloning and Southern and Northern transfers/analysis were performed using standard molecular biology procedures. Genomic phage clones were isolated from an Oregon- $R$ library (Promega) and cDNAs were obtained from embryonic libraries prepared with $\lambda$ gt 10 (Poole et al. 1985) and $\lambda$ zap (Stratagene) using poly $|\mathrm{A}|^{*}$ RNA isolated from Oregon-R embryos. A detailed description of our primer extension and RNase protection experiments is available upon request.

Amplification of genomic DNA flanking the pHlac insert was carried out by the inverse PCR protocol of Ochman et al. (1988) and described in Mellerick et al. (1992). Both strands of genomic DNA and cDNAs were sequenced by the chain-termination sequencing method (Sanger et al. 1977) adapted for Sequenase (v. 2.0, U.S. Biochemicall. Sequence analysis and data base searches were performed with the GCG software package (Devereux et al. 1984 ) and the BLAST Network Service (Altschul et al. 1990). Protein hydropathy analysis was carried out using the Kyte and Doolittle (1982) program.

\section{RNA localization}

An antisense digoxigenin-labeled riboprobe corresponding to all but the first 429 bp of the plx full-length cDNA was prepared using the RNA digoxigenin-labeling kit (Boehringer Mannheim) and the p7A16 plx cDNA plasmid. The RNA probe was reduced in size based on the protocol of Cox et al. (1984). Whole-mount embryo in situ hybridizations were performed based on the procedures of Tautz and Pfeifle (1989). Whole-mount in situ hybridizations of dissected ovaries were performed according to Ruohola et al. $11991 \%$.

\section{Recombinant protein generation and purification}

To functionally characterize the encoded protein of $p l x$ and prepare Plx antibodies, a full-length recombinant Plx protein containing a histidine tag fused to its amino terminus was generated using the pET expression system (Studier et al. 1990). Briefly, the ORF of $p l x$ was amplified from the p7A16 cDNA clone using PCR and inserted into the expression vector $\mathrm{PET}$ $16 \mathrm{~b}$ [Novagen/. The orientation and reading frame of the plx sequence was subsequently confirmed by DNA sequence analysis. Protein induction was performed according to Novagen protocols in the Escherichia coli [BL21 (DE3)] strain, and purification of the recombinant Plx was carried out according to the procedure of Shirakata et al. (1993). A more detailed description of this protocol is available on request.

\section{Antibody production}

To generate mouse polyclonal antibodies against Plx, the bacterially expressed protein was used to immunize mice based on the protocol of Oettinger et al. $\{1992\}$ with the following modifications. Briefly, the recombinant Plx was resolved by electrophoresis through an $8 \%$ polyacrylamide-SDS gel and transferred electrophoretically to an Immobilon-P membrane (Millipore) using standard procedures. For immunization, $B A L B / c$ 
female adult mice were anesthetized and a $0.6 \times 0.3 \cdot \mathrm{cm}$ strip of the Immobilon-P membrane containing $\sim 100 \mu \mathrm{g}$ of recombinant protein was implanted subcutaneously through a $1-\mathrm{cm}$ incision made along the dorsal midline at the level of the scapulae. Fifteen days later, $\sim 50 \mu \mathrm{g}$ of recombinant protein in a crushed polyacrylamide gel slice in $200 \mathrm{ml}$ of PBS/RIBI adjuvant system [1:1 (vol/vol), RIBI ImmunoChem Research Inc.] was injected subcutaneously. One month after the initial implantation, a second boost was administered by intraperitoneally injecting small pieces of nitrocellulose impregnated with a total of $\sim 50 \mu \mathrm{g}$ of Plx protein. The nitrocellulose chips were mixed with $100 \mu 1$ of dimethylsulfoxide (DMSO) plus an equal volume of PBS and sonicated to produce smaller shreds. Fifteen days after this final boost, mice were exanimated by bleeding out, and their sera saved at $-80^{\circ} \mathrm{C}$ for subsequent analysis.

\section{Immunohistochemistry}

The antibody-staining protocol was based on a procedure developed by N. Patel (1994) using the Vectastain ABC second antibody avidin/biotin HRP visualization reagents (Vector Labs). Detailed protocols are available on request. The antibodies and dilutions used were rabbit anti- $\beta$-gal (Promega, 1:250); rabbit anti-HRP (Cappel, 1:500); mouse anti-Plx, 1:800; mouse mAb 1D4 anti-fasciclin II, 1:10 (a gift from C. Goodman, California Institute of Technology, Pasadena); mouse mAb BP102, 1:20 /a gift from N. Patel, University of Chicago, IL); mouse mAb BP104 1:10 /also from N. Patel); mouse mAb 2A12, 1:20 〈N. Patel); and mouse mAb 22C10, 1:20 (a gift from S. Benzer, California Institute of Technology, Pasadenal.

For the immunostaining of Plx expressing transformed cultured S2 cells, cells were induced to express Plx, through copper induction (see Plx expression in S2 cells and cell aggregation assay, below). After a 24-hr recovery period the cells were washed twice with PBS, cross-linked to poly-L-lysine-precoated slides by formaldehyde fixation, and immunostained.

\section{Cell attachment assays}

Cell substratum attachment experiments were carried out according to the protocol of Ruoslahti et al. (1982) and Hayman et al. (1985) using cultured human MG63 cells (ATCC, CRL 1427 ). Microtiter wells were coated with $100 \mu \mathrm{l} /$ well of purificd $p l x$ recombinant protein $(2 \mu \mathrm{g} / \mathrm{ml})$ that had been dialyzed previously overnight with PBS or coated with fibronectin /GIBCO $\mathrm{BRL}$ ). Following an overnight incubation at room temperature, the coated wells were washed with PBS, blocked with BSA I1 $\mathrm{mg} / \mathrm{ml}$ ) (Sigma) for $30 \mathrm{~min}$ at $37^{\circ} \mathrm{C}$, and washed again with PBS. Cultured MG63 cells, split the day before the assay, were trypsinized, washed with PBS containing soybean trypsin inhibitor $(0.5 \mathrm{mg} / \mathrm{ml})$, and then resuspended at $2.5 \times 10^{5} / \mathrm{ml}$ in Dulbecco's modified Eagle medium (DMEM) containing $2 \mathrm{mg} / \mathrm{ml}$ of BSA. Cell suspensions were added to wells $(100 \mu \mathrm{l} /$ well $)$ and incubated at $37^{\circ} \mathrm{C}$ for $60 \mathrm{~min}$. The microtiter wells were then washed with PBS to remove unbound cells, and the bound cells were then fixed with formaldehyde $\$ 10 \%$ in PBS $\}$ for $20 \mathrm{~min}$. To enhance visualization, cells were stained in $1.0 \%$ toluidine blue overnight at room temperature and then washed with water. Cell attachment inhibition experiments were done according to Hayman et al. (1985) following the same procedure as the cell attachment assays except that $1 \mathrm{mg} / \mathrm{ml}$ of GRGDSP peptide (GIBCO BRL) was added to the cell suspension before their addition to the microtiter wells. For control experiments, the GRGESP peptide (GIBCO BRL) was added to the cell suspension instead of GRGDSP peptide at the same concentration.

\section{Plx expression in $\mathrm{S} 2$ cells and cell aggregation assay}

S2 cells were grown using standard culture conditions at room temperature in Schneider's Drosophila medium (GIBCO BRL). The plx ORF was inserted into the pRmHa-3 expression vector containing the metallothione promoter (Bunch et al. 1988). For transient expression of $\mathrm{Plx}$, the expression plasmid was transformed into S2 cells using the calcium phosphate-mediated transfection procedure (Sambrook et al. 1989). Twenty-four hours after transfection, the cells were either subjected to immunostaining with Plx polyclonal antibodies or treated with 0.7 $\mathrm{muCuSO}_{4}$ at a density of $1 \times 10^{6}$ cells $/ \mathrm{ml}$ overnight on a rotary shaker at $25^{\circ} \mathrm{C}$ followed by $\mathrm{Plx}$ immunostaining or cell aggregation assays. Aggregation assays were performed according to Nose et al. (1992).

To generate stable cell lines that express $\mathrm{Plx}, 20 \mu \mathrm{g}$ of the above pRmHa-3plx plasmid and $1 \mu \mathrm{g}$ of the pcopHyg plasmid (containing the hygromycin-resistant gene; Rio et al. 1986) were cotransfected into S2 cells. Three days later, hygromycin /Calbiochem 1 was added to the medium at a concentration of 200 $\mu \mathrm{g} / \mathrm{ml}$. After 4 weeks of selection, with medium changed every 5 days, Plx-expressing cells were selected by the immunopanning technique of Wysocki and Sato (1978), using anti-Plx mouse antisera and goat anti-mouse IgG (Boehringer Mannheiml as the secondary antibody.

\section{Electron microscopy}

Dissections from first-instar $(6-10 \mathrm{hr})$ and second-instar $(30-36$ hrl wild-type and plx larvae were prepared and sectioned using standard procedures for the transmission electron microscopic viewing of plastic embedded thin sections. Briefly, larvae were rinsed in phosphate-buffered saline, transferred to $2 \%$ glutaraldehyde in 100 m.u sodium cacodylate buffer $(\mathrm{pH} 7.4)$, and then dissected. Larval body slices, each containing abdominal segments $5-8$, were transferred to fresh $2 \%$ glutaraldehyde in cacodylate buffer. After $7 \mathrm{hr}$ at room temperature, the slices were postfixed in $1 \% \mathrm{OsO}_{4}$ in the cacodylate buffer at $4^{\circ} \mathrm{C}$ overnight, rinsed in buffer, and then dehydrated in a graded series of ethanol followed by plastic embedding in Epon using standard procedures. Following the examination of $10-\mu \mathrm{m}$-thick sections $\mid$ to identify appropriate regions for electron microscopy (EM) viewingl, serial transverse thin sections were collected from different regions of the abdominal segments 7 and 8, stained with uranyl acetate and lead citrate, and then viewed with a Joel $100 \mathrm{CX}$ operating at an accelerating voltage of $80 \mathrm{kV}$.

\section{Acknowledgments}

We are indebted to Shirley House for excellent technical support and guidance in the preparation of the Plx antibody. We thank James Nagle and the NINDS sequencing facility for help with DNA sequencing and Virginia Tanner of the NINDS Electron Microscopy Facility for technical support in EM. We acknowledge helpful discussions with Brian Mozer, Howard Nash, Jim Kennison, and Ravi Kambadur. We also thank Nipam Patel, Corey Goodman, Seymour Benzer, and members of their laboratories for antibodics used during the course of these studies (N. Patel, BP102 and 2Al2; C. Goodman, anti-Fas II and BP104; S. Benzer, 22C101. We are grateful to Sven Beushausen, Howard Nash, Harold Gainer, Lynn Hudson, and Brian Mozer for critical reading of the manuscript. We are also indebted to Harold Gainer for his advice and support throughout the duration of this project.

The publication costs of this article were defrayed in part by payment of page charges. This article must therefore be hereby 
marked "advertisement" in accordance with 18 USC section 1734 solely to indicate this fact.

\section{Note}

The GenBank accession number for the plx DNA sequence is U50542.

\section{References}

Adams, J.C. and J. Lawler. 1993. Diverse mechanisms for cell attachment to platelet thrombospodin. $/$. Cell Sci. 104: 1061-1071.

Altschul, S., F.W. Gish, W. Miller, E.W. Myers, and D.J. Lipman. 1990. Basic local alignment search tool. I. Mol. Biol. 215: 403-410.

Argraves, W.S., S. Suzuki, H. Arai, K. Thompson, M.D. Pierschbacher, and E. Ruoslahti. 1987. Amino acid sequence of the human fibronectin receptor. J. Cell Biol. 105: 1183-1190.

Bevilacqua, M., E. Butcher, B. Furie, B. Furie, M. Gallatin, M. Gimbrone, J. Harlan, K. Kishimoto, L. Lasky, R. McEver, J. Paulson, S. Rosen, B. Seed, M. Siegelman, T. Springer, L. Stoolman, T. Tedder, A. Varki, D. Wagner, I. Weissman, and G. Zimmerman. 1991. Selectins: A family of adhesion receptors. Cell 67: 233.

Bourdon, M.A., T. Krusius, S. Campbell, N.B. Schwartz, and E. Ruoslahti. 1987. Identification and synthesis of a recognition signal for the attachment of glycosaminoglycans to proteins. Proc. Natl. Acad. Sci. 84: 3194-3198.

Bunch, T.A., Y. Grunblat, and L.S. Goldstein. 1988. Characterization and use of the Drosophila methallotionein promoter in cultured Drosophila melanogaster cells. Nucleic Acids Res. 16: 1043-1061.

Calvete, J.J., A. Henschen, and J. Gonzalez-Rodriguez. 1991. Assignment of disulphide bonds in human platelet GPIIIa. A disulphide pattern for the alpha-subunits of the integrin family. Biochem. I. 15: 63-71.

Campos-Ortega, J.A. and V. Hartenstein. 1985. The embryonic development of Drosophila melanogaster Springer-Verlag, Berlin, Germany.

Cardin, A.D. and H.J.R. Weintraub. 1989. Molecular modeling of protein-glycosaminoglycan interactions. Arteriosclerosis 9: 21-32.

Chou, P.Y. and G.D. Fasmen. 1978. Emprical predictions of protein conformations. Annu. Rev. Biochem. 47: 251-276.

Cox, K.H., D.V. Deleon, L.M. Angerer, and R.C. Angerer. 1984. Detection of mRNAs in sea urchin embryos by in situ hybridization using asymmetric RNA probes. Dev. Biol. 101: 485-502.

Devereux, J., P. Haeberli, and O. Smithies. 1984. A comprehensive set of sequence analysis programs for the VAX. Nucleic Acids Res. 11: 387-395.

Di Nocera, P.P., M.E. Digan, and I. Dawid. 1983. A family of oligoadenylated transposable sequences in Drosophila melanogaster. I. Mol. Biol. 168: 715-727.

Elkins, T., K. Zinn, L. McAllister, F.M. Hoffmann, and C.S. Goodman. 1990. Genetic analysis of a Drosophila neural cell adhesion molecule: Interaction of fasciclin I and Abelson tyrosine kinase mutations. Cell 60: 565-575.

Fessler, I.H. and L.I. Fessler. 1989. Drosophila extracellular matrix. Annu. Rev. Cell Biol. 5: 309-339.

Garnier, J., D.J. Osguthorpe, and B. Robson. 1978. Analysis of the accuracy and implications of simple methods for predicting the secondary structure of globular proteins. I. Mol. Biol. 120: $97-120$.
Goodman, C.S. and C.Q. Doe. 1993. Embryonic development of the Drosophila central nervous system. In The development of Drosophila melanogaster (ed. M. Bate and A.M. Arias), pp. 1131-1206, Cold Spring Harbor Laboratory Press, Cold Spring Harbor, NY.

Grenningloh, G., A.J. Bieber, E.J. Rehm, P.M. Snow, Z.R. Traquina, M. Hortsch, N.H. Patel, and C.S. Goodman. 1990. Molecular genetics of neuronal recognition in Drosophila: Evolution and function of immunoglobulin superfamily cell adhesion molecules. Cold Spring Harbor Symp. Quant. Biol. 55: 327-340.

Hayman, E.G., M.D. Pierschbacher, S. Suzuki, and E. Ruoslahti. 1985. Vitronectin-A major cell attachment-promoting protein in fetal bovine serum. Exp. Cell Res. 160: 245-258.

Hiromi, Y., A. Kuroiwa, and W.J. Gehring. 1985. Control elements of the Drosophila segmentation gene fushi tarazu. Cell 43: 603-613.

Hunter, D.D., B.E. Porter, I.W. Bulock, S.P. Adams, J.P. Merlie, and I.R. Sanes. 1989. Primary sequence of a motor neuronselective adhesive site in the synaptic basal lamina protein, s-laminin. Cell 59: 905-913.

Hursh, D.A., M.E. Andrews, and R.A. Raff. 1987. A sea urchin gene encodes a polypeptide homologous to epidermal growth factor. Science 237: 1487-1490.

Hynes, R.O. 1986. Molecular biology of fibronectin. Annu. Rev. Cell Biol. 1: 67-83.

- 1992. Integrins: Versatility, modulation, and signaling in cell adhesion. Cell 69: 11-25.

Hynes, R.O. and A.D. Lander. 1992. Contact and adhesive specificities in the associations, migrations, and targeting of cells and axons. Cell 68: 303-322.

Jessell, T.M. 1988. Adhesion molecules and the hierarchy of neural development. Neuron 1:3-13.

Jolles, P. 1994. Proteoglycans. Brikhauser-Verlag, Basal, Switzerland.

Keith, F.I. and N.J. Gay. 1990. The Drosophila membrane receptor Toll can function to promote cellular adhesion. EMBO I. 9: 4299-4306.

King, R.C. 1970. Ovarian development in Drosophila melanogaster. Academic Press, New York.

Krantz, D.E. and S.L. Zipursky. 1990. Drosophila chaoptin, a member of the leucine-rich repeat family, is a photoreceptor cell-specific adhesion molecule. EMBO I. 9: 1969-1977.

Kyte, J. and R.F. Doolittle. 1982. A simple method for displaying the hydropathic character of a protein. /. Mol. Biol. 157: 105132.

Landschulz, W.H., P.F. Johnson, and S.L. McKnight. 1988. The leucine zipper: A hypothetical structure common to a new class of DNA binding proteins. Science 240: 1759-1764.

Lindsley, D.L. and G. Zimm. 1987. The genome of Drosophila melanogaster (part 3); rearangements. Dros. Inf. Serv. 65: 25.

Lipman, D.I. and W.R. Pearson. 1985. Rapid and sensitive protein similarity searches. Science 227: 1435-1441.

Manning, G. and M.A. Krasnow. 1993. Development of the Drosophila tracheal system. In The Development of Drosophila melanogaster (ed. M. Bate and A.M. Arias), pp. 609686. Cold Spring Harbor Laboratory Press, Cold Spring Harbor, NY.

Mellerick, D.M., I.A. Kassis, S.-D. Zhang, and W.F. Odenwald. 1992. castor encodes a novel Zinc finger protein required for the development of a subset of CNS neurons in Drosophila. Neuron 9: 789-803.

Nakamura, T., J. Hillova, R. Mariage-Samson, and M. Hill. 1988. Molecular cloning of a novel oncogene generated by DNA recombination during transfection. Oncogene Res. 2: $357-370$. 
Nakamura, T., I. Hillova, R. Mariage-Samson, M. Onno, K. Huebner, L.A. Cannizzaro, L. Boghosian-Sell, C.M. Croce, and M. Hill. 1992. A novel transcriptional unit of the tre oncogene widely expressed in human cancer cells. Oncogene 7: 733-741.

Nambu, J.R., R.G. Franks, S. Hu, and S.T. Crews. 1990. The single-minded gene of Drosophila is required for the expression of genes important for the development of CNS midline cells. Cell 63: 63-75.

Noirot, C. and C. Noirot-Thimotee. 1982. The structure and development of the tracheal system. In Insect ultrastructure (ed. R.C. King and H. Akai|, pp. 351-481. Plenum Press, NY.

Nose, A., V.B. Mahajan, and C.S. Goodman. 1992. Connectin: A homophilic cell adhesion molecule expressed on a subset of muscles and the motoneurons that innervate them in Drosophila. Cell 70: 553-567.

Ochman, H., A.S. Gerber, and D.L. Hartl. 1988. Genetic applications of an inverse polymerase chain reaction. Genetics 120: $621-625$.

Oettinger, H.F., R. Pasqualini, and M. Bernfield. 1992. Recombinant peptides as immunogens: A comparison of protocols for antisera production using the pGEX system. BioTechniques 12: $544-549$.

Patel, N.H. 1994. Imaging neuronal subsets and other cell types in whole-mount Drosophila embryos and larvae using antibody probes. Methods Cell Biol. 44: 445-487.

Pierchbacher, M.D. and E. Ruoslahti. 1984. Cell attachment activity of fibronectin can be duplicated by small synthetic fragments of the molecule. Nature 303: 31-33.

Poole, S.J., L.M. Kauvar, B. Drees, and T. Kornberg. 1985. The engrailed locus of Drosophila; structural analysis of an embryonic transcript. Cell 40: 37-43.

Reichardt, L.F. and K.L. Tomaselli. 1991. Extracellular matrix molecules and their receptors: Functions in neural development. Annu. Rev. Neurosci. 14: 531-570.

Rio, D.C., F.A. Laski, and G.M. Rubin. 1986. Identification and immunochemical analysis of biologically active Drosophila P element transposase. Cell 44: 21-32.

Ruohola, H., K.A. Bremer, D. Baker, J.R. Swedlow, L.Y. Jan, and Y.N. Jan. 1991. Role of neurogenic genes in establishment of follicle cell fate and oocyte polarity during oogenesis in Drosophila. Cell 9: 433-449.

Ruoslahti, E., E.G. Hayman, M.D. Pierschbacher, and E. Engvall. 1982. Fibronectin: Purification, immunochemical properties and biological activities. Methods Enzymol. 82: 803831 .

Sambrook, J., E.F. Fritsch, and T. Maniatis. 1989. Molecular cloning: A laboratory manual. Cold Spring Harbor Laboratory Press, Cold Spring Harbor, NY.

Sanger, F., S. Nicklen, and A.R. Coulson. 1977. DNA sequencing with chain-terminating inhibitors. Proc. Natl. Acad. Sci. 74: 54-63.

Shirakata, M., F.K. Friedman, Q. Wei, and B.M. Paterson. 1993. Dimerization specificity of myogenic helix-loop-helix DNA-binding factors directed by nonconserved hydrophilic residues. Genes \& Dev. 7: 2456-2470.

Snow, P.M., A.J. Bieber, and C.S. Goodman. 1989. Drosophila fasciclin III: A novel homophilic adhesion molecule. Cell 59: $313-322$.

Staatz, W.D., K.F. Fok, M.M. Zutter, S.P. Adams, B.A. Rod riguez, and S.A. Santoro. 1991. Identification of a tetrapeptide recognition sequence for the $\alpha 2 \beta 1$ integrin in collagen. I. Biol. Chem. 266: 7363-7367.

Strubin, M., B. Mach, and E.O. Long. 1984. The complete sequence of the mRNA for the HLA-DR-associated invarient chain reveals a polypeptide with an unusual transmembrane polarity. EMBO /. 3: 869-872.

Studier, F.W., A.H. Rosenberg, J.J. Dunn, and J.W. Dubendorff 1990. Use of T7 RNA polymerase to direct expression of cloned genes. Methods Enzymol. 185: 60-89.

Suyemitsu, T., T. Asami-Yoshizumi, S. Noguchi, Y. Tonegawa, and $\mathrm{K}$. Ishihara. 1989. The exogastrula-inducing peptides in embryos of the sea urchin, Anthocidaris crassispina, isolation and determination of the primary structure. Cell Differ. Dev. 26: 53-66.

Suzuki, S., W.S. Argraves, R. Pytela, H. Arai, T. Krusius, M.D. Pierschbacher, and E. Ruoslahti. 1986. cDNA and amino acid sequences of the cell adhesion protein receptor recog nizing vitronectin reveal a transmembrane domain and ho mologies with other adhesion receptors. Proc. Natl. Acad. Sci. 83: 8614-8618.

Takeichi, M. 1990. Cadherins: A molecular family important in selective cell-cell adhesion. Annu. Rev. Biochem. 59: 237 252 .

- 1991. Cadherin cell adhesion receptors as a morphogenetic regulator. Science 251: 1451-1455.

Tautz, D. and C. Pfeifle. 1989. A non-radioactive in situ hybridization method for the localization of specific RNAs in Drosophila embryos reveals translational control of the segmentation gene hunchback. Chromosoma 98: 81-85.

Titani, K., K. Takio, M. Handa, and Z.M. Ruggeri. 1987. Amino acid sequence of the von Willebrand factor-binding domain of platelet membrane glycoprotein Ib. Proc. Natl. Acad. Sci. 84: $5610-5614$.

Van Vactor, D., H. Sink, D. Fambrough, R. Tsoo, and C.S. Goodman. 1993. Genes that control neuromuscular specificity in Drosophila. Cell 73: 1137-1153.

Williams, A.F. and A.N. Barclay. 1988. The immunoglobin superfamily - domains for cell surface recognition. Annu. Rev. Immunol. 6: 381-405.

Wysocki, L.J. and V.L. Sato. 1978. Panning for lymphocytes: A method for cell selection. Proc. Natl. Acad. Sci. 75: 2844 2848 .

Zipursky, S.L., T.R. Venkatesh, D.B. Teplow, and S. Benzer. 1984. Neuronal development in the Drosophila retina: Monoclonal antibodies as molecular probes. Cell 36: 15-26. 


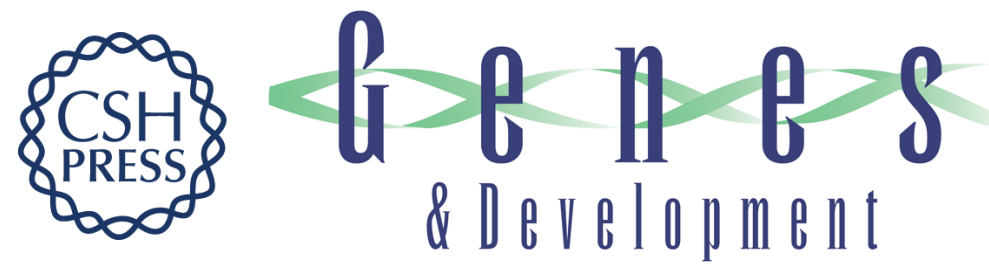

\section{Pollux, a novel Drosophila adhesion molecule, belongs to a family of proteins expressed in plants, yeast, nematodes, and man.}

S D Zhang, J Kassis, B Olde, et al.

Genes Dev. 1996, 10:

Access the most recent version at doi:10.1101/gad.10.9.1108

References This article cites 60 articles, 16 of which can be accessed free at:

http://genesdev.cshlp.org/content/10/9/1108.full.html\#ref-list-1

License

Email Alerting

Service

Receive free email alerts when new articles cite this article - sign up in the box at the top right corner of the article or click here.

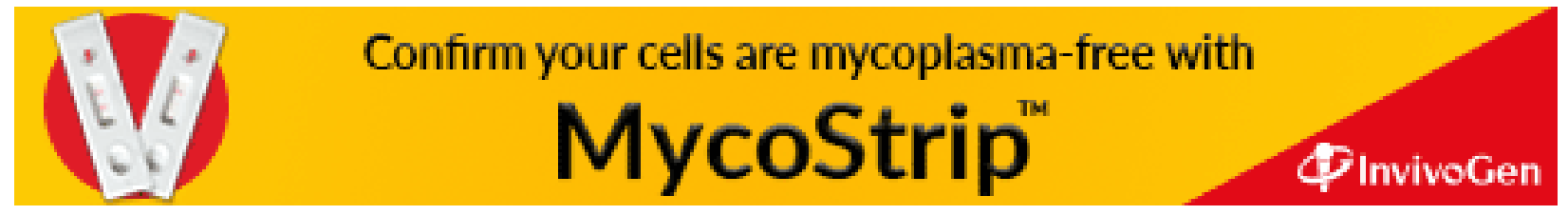

